
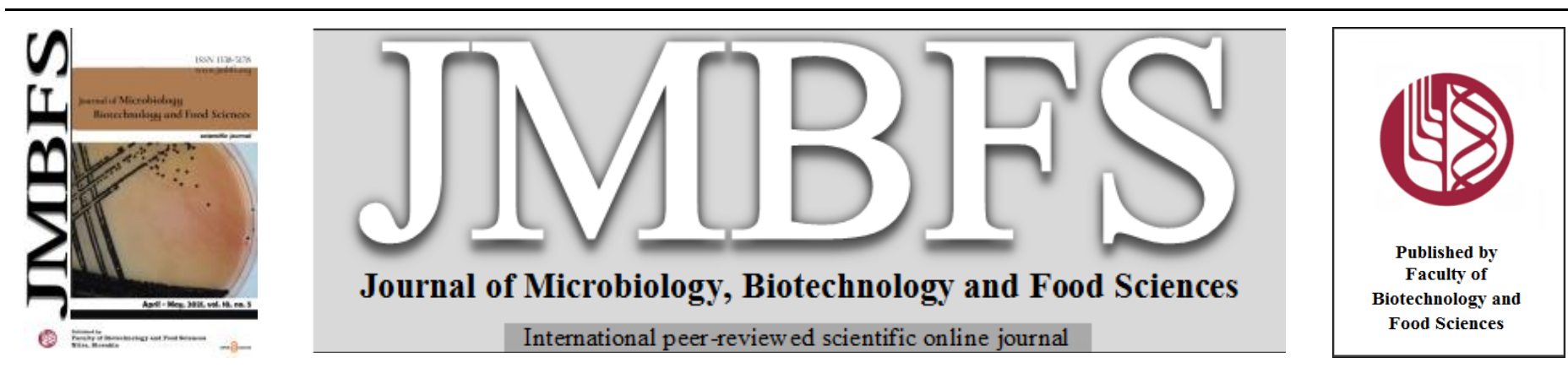

\title{
Stevia rebaudiana LEAF EXTRACT REDUCES BLOOD GLUCOSE AND VISCERAL FAT ACCUMULATION IN ALLOXAN-INDUCED DIABETIC MICE
}

\author{
Darlene Fe P. Castro ${ }^{l}$, Niño John Lentenee C. Bernardo ${ }^{l}$, Froilan Bernard R. Matias ${ }^{\text {I* }}$ \\ Address(es): Froilan Bernard Matias, \\ ${ }^{1}$ College of Veterinary Science and Medicine, Central Luzon State University, Science City of Muñoz 3120 Nueva Ecija, Philippines.
}

*Corresponding author: fbrmatias@ clsu.edu.ph

https://doi.org/10.15414/jmbfs.3347

\section{ARTICLE INFO}

Received 27. 6. 2020

Revised 11. 11. 2020

Accepted 23. 11. 2020

Published 1. 4. 2021

Regular article

open $\partial$ ACcess

\begin{abstract}
Diabetes is a major global epidemic currently affecting millions of people. Unfortunately, the present pharmacological approach for the management of this serious disease has still a lot of rooms for improvement and innovation, which behooves the exploration of newer and safer agents. S. rebaudiana has emerged as a natural non-caloric sweetener and it is reported to have several health benefits including its antidiabetic effects. Thus, an in-depth investigation of this plant is needed in order to elucidate further its antidiabetic properties and its influence on the histological integrity of the major organs involved in carbohydrate metabolism.

Inbred ICR mice $(\mathrm{n}=36)$ were randomly into six groups - one group served as the negative control while other five groups were given intraperitoneally with alloxan to induce diabetes and divided into the following groups: positive control (untreated group), glibenclamide $(0.2 \mathrm{mg} / 20 \mathrm{~g})$ treated, and $100 \%, 60 \%$, and $10 \%$ stevia leaf extract treated, respectively. The experiment was conducted for two weeks where the treatments were orally given once a day and the following were evaluated: changes in body weight, fasting blood sugar (fBGL), oral glucose tolerance test (OGTT), and gross and microscopic changes in the pancreas, liver, and kidney. Results showed that though stevia has no effect on the reduction of body weight, the different concentrations have comparable effects with glibenclamide in fBGL and OGTT. Furthermore, the different concentrations of stevia leaf extracts showed lesser visceral fat accumulation grossly, and lesser cellular degradation, microscopically.
\end{abstract}

Keywords: diabetes mellitus, alloxan-induced diabetes, glibenclamide, Stevia rebaudiana

\section{INTRODUCTION}

Diabetes mellitus is a group of diseases characterized by hyperglycemia and varying degrees of insufficient insulin effects. The type 2 diabetes mellitus pathogenesis involves insulin resistance and dysfunctional secretion of insulin by the $\beta$ cells of the pancreas (Gupta et al., 2010). This condition raises the risk of several complications, mostly by microvascular damage (retinopathy, nephropathy, and neuropathy). It is associated with reduced life expectancy, significant morbidity and diminished quality of life (Chehade et al., 2013) Diabetes mellitus, particularly type 2 , is a chronic metabolic disorder with an increasing trend worldwide. It has become an epidemic in some regions of the world and the number of people with the disease is expected to double in the next 10 years due to factors like increase in aging population and changes in lifestyle, thereby adding to the burden for public health (Sicree $\boldsymbol{e t}$ al., 2006). According to the World Health Organization (1999), there are approximately 177 million people with diabetes worldwide, which powered and maintained the interest of researchers to further understand the disease's pathophysiology, the risk factors associated with it and develop drugs and other treatments to address the condition.

One of the famous ways of treating chronic diseases is the use of complementary/ alternative medicine (Eisenberg et al., 1998). People with diabetes tend to use non-prescribed supplements (herbal, vitamin, mineral, or others). These methods are reported to deliver more promising results and lesser side effects. Several clinical trials are also conducted to test the effectiveness and efficiency of the aforementioned treatments, especially herbal remedies. One of the plants that currently receive increasing attention is $S$. rebaudiana. It is famous for its sweet taste and commercial value all over the world as a sugar substitute in foods, beverages, and medicines. It is a plant that offers sweetness with fewer calories and does not show any side effects after consumption on human health (Gupta $\boldsymbol{e t}$ al., 2013). Moreover, it has been reported that S. rebaudiana shows the ability to maintain a blood glucose level with glucose tolerance enhancement in diabetic rats. Stevia could also cause hypoglycemia in patients with diabetes through decreasing glycogenolysis and gluconeogenesis and absorbing glucose in the duodenum. In addition, anti-hyperglycemic and antioxidative potential of stevia and its glycoside were detected in several tissues such as the kidney, liver, and pancreas (Misra et al., 2011). In the study of Sytar et al. (2015), stevia leaves contain different phenolic compounds that showed high antioxidant activities.
The current study assessed the ability of $S$. rebaudiana to reduce blood glucose levels and the accumulation of visceral fats in ICR mice with alloxan-induced diabetes. Specifically, the study evaluated the effects of stevia leaf extracts at different concentrations on changes in body weight, fBGL after and before giving the daily treatments and OGTT, Also, at the end of the treatment period, gross and microscopic changes in the pancreas, liver, and kidney were described and compared.

\section{MATERIAL AND METHODS}

Preparation of stevia leaf extract

The stevia plants (S. rebaudiana) were collected from the highland province of Benguet that has an annual temperature that ranges from 15 to $23^{\circ} \mathrm{C}$. About 500 $\mathrm{g}$ of dried stevia leaves were subjected to ethanol extraction then subjected to rotary evaporation. The collected extract was stored in a light-proof amber bottle and placed in refrigeration $\left(4^{\circ} \mathrm{C}\right)$ until further used.

\section{Experimental animals}

Inbred ICR mice $(n=36)$, about six to eight weeks of age were used in the study. The mice were housed in a temperature-controlled room $\left(21^{\circ} \mathrm{C} \pm 2^{\circ} \mathrm{C}\right)$, with a 12 -h light/dark cycle (Fawcett, 2012) at the Mouse Research and Breeding Facility at the Animal Control Center, Central Luzon State University (CLSU), and given with ad libitum supply of feeds and water. After one week of acclimatization, the mice were randomly divided into six groups. The protocol for handling and experimentation in laboratory animals employed at the College of Veterinary Science and Medicine followed the institutional animal care and use committee (IACUC) of the university.

\section{Experimental design}

One of the six groups was designated as the negative control group, while the other five groups were intraperitoneally given with $3 \%(\mathrm{w} / \mathrm{v})$ alloxan $(70 \mathrm{mg} / \mathrm{kg})$ to induce diabetes. Among five groups with induced diabetes, one group served as the positive control (untreated group) while the remaining four groups were orally treated using a gavage needle with the following: glibenclamide 
$(0.2 \mathrm{mg} / 20 \mathrm{~g}), 100 \%, 60 \%$, and $10 \%$ stevia leaf extract, respectively. The different treatments were given for a period of two weeks.

Table 1 Treatment groups

\begin{tabular}{lcc}
\hline Treatments & N & Alloxan-induced diabetes mellitus \\
\hline Negative control & 6 & No \\
Positive control & 6 & Yes \\
Glibenclamide & 6 & Yes \\
$100 \%$ stevia leaf extract & 6 & Yes \\
$60 \%$ stevia leaf extract & 6 & Yes \\
$10 \%$ stevia leaf extract & 6 & Yes \\
\hline
\end{tabular}

\section{Monitoring of body weight and blood glucose level}

Changes in body weight of mice with alloxan-induced diabetes were determined by getting the difference in body weight before and after treatment within the two weeks experimental window. The fBGL was determined using a handheld glucometer (EasyTouch ${ }^{\circledR}$ Glucose Monitoring System). The mice were fasted for eight hours prior to the procedure. A drop of blood sample was drawn from the tail and was directly applied on the glucose strip inserted to the apparatus. The measured glucose level will appear on the monitor.

\section{Oral glucose tolerance test}

Oral glucose tolerance test was conducted in mice after the two-week observation period. The mice were fasted for eight hours and their baseline blood glucose levels were determined using the procedure described previously. After this, glucose solution was administered ( $2 \mathrm{~g} / \mathrm{kg}$ body weight) orally using a gavage needle. The blood glucose levels were measured at $0,10,20,30,40$ and $50 \mathrm{~min}$ after the glucose oral administration. The values were plotted in a graph to make a glucose tolerance curve for each group (Mouse Metabolic Phenotyping Center, 2012).

\section{Gross and histopathological examination}

At the end of observation period, selected animals from each treatment were sacrificed. The liver, pancreas, and kidneys were collected from each mouse. The organs were fixed in $10 \%$ buffered formalin and prepared for tissue processing. The prepared tissue slides were stained using hematoxylin and eosin stains. The slides were examined under a microscope for lesions and notable observation.

\section{Statistical analysis}

The measured body weight was presented as mean \pm standard deviation (SD). The data were analyzed using analysis of variance (ANOVA) followed by
Fisher's least significant difference (LSD). The level of significant difference was set at $95 \%$ confidence interval at a $\mathrm{p}$-value of $\leq 0.05$.

\section{RESULTS AND DISCUSSION}

\section{Body weight and blood glucose level}

Table 2 The changes in body weight before and after treatment with glibenclamide and different concentrations of stevia leaf extract

\begin{tabular}{llc}
\hline Treatments & N & Mean \pm SD \\
\hline Negative control & 6 & $-1.57 \pm 1.40^{\mathrm{b}}$ \\
Positive control & 6 & $1.86 \pm 1.35^{\mathrm{a}}$ \\
Glibenclamide & 6 & $1.57 \pm 0.98^{\mathrm{a}}$ \\
$100 \%$ stevia leaf extract & 6 & $1.00 \pm 1.41^{\mathrm{a}}$ \\
$60 \%$ stevia leaf extract & 6 & $0.83 \pm 0.75^{\mathrm{a}}$ \\
$10 \%$ stevia leaf extract & 6 & $1.50 \pm 0.55^{\mathrm{a}}$ \\
\hline
\end{tabular}

Mean + SD with different superscript letters in a column are significantly different at 5\% level of significance.

Table 2 shows the mean + SD body weight difference of mice per group before and after treatment. All groups gained weight before the start of treatment, with the positive control group having the highest. All diabetic groups had a decrease in weight after treatment (with positive control having the highest loss), except for the negative control group. Results of the statistical analysis emphasized the significant difference of mean body weight changes of negative control compared with groups treated with alloxan-induced diabetes.

Statistical analysis of the weight changes shows a significant difference $(5 \%$ level of significance) before and after treatment on all diabetic groups versus the negative control group. Treated and untreated diabetic groups showed no significant difference between each other. As shown in Figure 1, groups with alloxan-induced diabetes showed a decrease in body weight. Same results were obtained from the studies of Assaei et al. (2016), and Singh and Pathak (2015), wherein all groups given with alloxan (diabetic groups), whether treated or not, resulted in weight reduction. American Diabetes Association (2009) also mentioned that diabetic patients suffered several symptoms such as gradual weight loss as a consequence of insulin or insulin mobilization insufficiency. The decrease in body weight of diabetic mice can be attributed to catabolism of protein, even though the food intake was greater in diabetic rats than control. Due to insulin deficiency, protein content was decreased in muscular tissue by proteolysis (Raparia et al., 2012). In the study of Abdellatif (2013), the diabetes caused by STZ administration increases fat and protein mobilization in skeletal muscle, inducing significant weight loss, as was also observed in the present study.

Table 3 Mean percent changes in fasting blood glucose level $(\mathrm{mg} / \mathrm{dL})$ of mice with alloxan-induced diabetes and either treated with glibenclamide or different concentration of stevia leaf extract

\begin{tabular}{lccc}
\hline \multirow{2}{*}{ Groups } & Treatments & \multicolumn{2}{c}{ Mean percent (\%) difference of fBGL } \\
\cline { 3 - 4 } & Negative control & Day 5, after daily dose & Day 8, before daily dose \\
\hline 1 & Positive control & $1.47 \uparrow$ & $4.47 \uparrow$ \\
2 & Glibenclamide & $18.21 \downarrow$ & $17.41 \uparrow$ \\
3 & $100 \%$ stevia leaf extract & $17.63 \downarrow$ & $2.64 \uparrow$ \\
4 & $60 \%$ stevia leaf extract & $14.53 \downarrow$ & $12.57 \downarrow$ \\
5 & $10 \%$ stevia leaf extract & $23.79 \downarrow$ & $0.97 \uparrow$ \\
6 & Legend: Arrow up $(\uparrow)$ denotes increase in mean percent difference while arrow down $(\downarrow)$ denotes otherwise.
\end{tabular}

Mice from all groups were tested for fBGL at day 5 after administering the daily dose, and at day 8 before giving the daily dose. Mean percent difference of fBGL was determined using day 0 as the baseline value.

Among groups, only negative and positive control groups showed an increase in the post-treatment fBGL $(6.47$ and $1.80 \%$, respectively) at day 5. All groups exhibited a decrease in fBGL (ranges from 14.53 to $23.79 \%$ ) with the group treated with $10 \%$ stevia leaf extract as the highest, followed by groups treated with glibenclamide, and $100 \%$ and $60 \%$ stevia leaf extract. Pretreatment fBGL at day 8 shows an increase in mean percent difference in all groups $(0.97$ to $17.41 \%)$, except for groups treated with $100 \%$ and $10 \%$ stevia leaf extract, $(12.57$ and $13.69 \%$ decrease, respectively). The results showed that there was a remarkable decrease in fBGL, if testing was done after giving either glibenclamide or any concentration of stevia leaf extract. On the other hand, giving of treatments after fBGL generally showed an increase in value, except for $100 \%$ and $10 \%$ stevia leaf extracts.

According to Assaei et al., (2016) during diabetes or insulin resistance, failure of insulin-stimulated glucose uptake by skeletal fat and muscle causes high glucose concentration in blood. Consequently, glucose uptake by insulin-independent tissues, oxidant production and impaired antioxidant defenses occur. The use of glibenclamide in mild to severe diabetes mellitus in rats showed a decreased blood glucose concentration and an increased level of insulin (Sokolovska et al.,
2012). It is a sulfonylurea that has been commonly used to treat type 2 diabetes since it can stimulate beta cells of the pancreas to produce insulin (Proks et al., 2002). On the other hand, stevia has anti-hyperglycemic and anti-oxidative potential due to some of its components which may stimulate the beta cells to release insulin (Jeppesen et al., 2000) leading to improvement in the carbohydrate-metabolizing enzymes and thus establishing lower to normal blood glucose level. In addition, the beneficial effects of stevia as an antihyperglycemia was reported to be associated with the increased in peroxisome proliferator-activated receptor- $\gamma(\operatorname{PPAR} \gamma)$, a nuclear hormone receptor that maintains glucose level, and insulin mRNA levels (Gupta et al., 2010; Assaei $\boldsymbol{e t}$ al., 2016).

\section{Oral glucose tolerance test}

Fasting plasma or blood glucose concentrations between 100 and $125 \mathrm{mg} / \mathrm{dl}$ necessitates the use of glucose tolerance test. The OGTT is an important instrument for identifying the pre-diabetic metabolic state in humans (Kim et al., 2016). OGTT results in Table 4 showed a remarkable difference of the positive control group compared with other groups. 


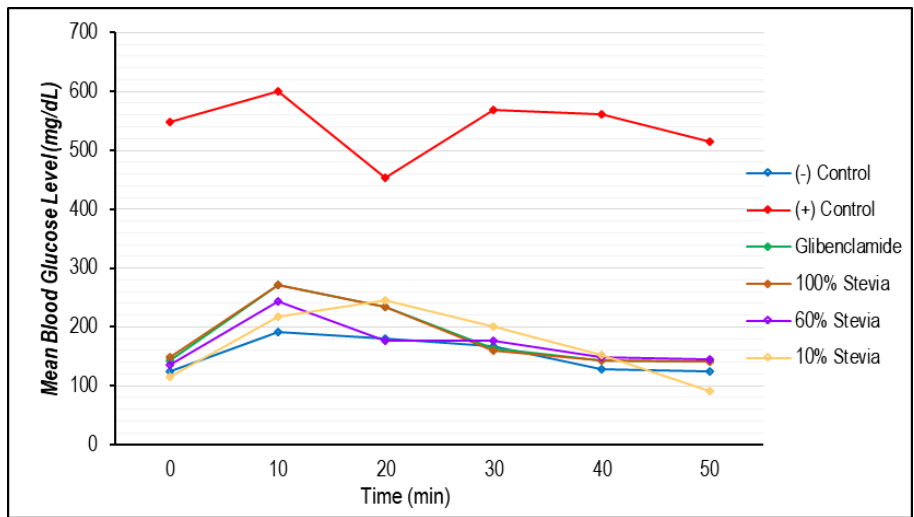

Figure 1 Oral glucose tolerance test results of alloxan-induced diabetic mice treated either with glibenclamide or different concentrations of stevia leaf extract

As shown in Figure 2, all groups (except for the positive control) manifested a less than $200 \mathrm{mg} / \mathrm{dL}$ baseline blood glucose values that eventually increased and peaked after 10 min (20 min for group treated with $100 \%$ stevia leaf extract). A gradual decline was observed and eventually returned to the baseline glucose value after $50 \mathrm{~min}$. The positive control group showed a baseline blood glucose level of more than $500 \mathrm{mg} / \mathrm{dL}$ that peaked after $10 \mathrm{~min}$ then drastically decreased, even lower than the baseline value, after $20 \mathrm{~min}$. The blood glucose level then returned to its baseline value.

Lachin and Reza (2012) stated that alloxan treatment evokes a sudden rise in insulin secretion in the presence or absence of glucose and this insulin release occurs for short duration followed by the complete suppression of the islet response to glucose even when high concentrations of glucose were used. Results of the present study indicate that stevia has the ability to prevent hyperglycemia Stevia has functional components that help in regulating insulin release from pancreatic beta cells, thus assisting and improving carbohydrate metabolism resulting to lower to normal blood glucose level (Assaei et al., 2016).

\section{Gross and histopathological examination}

After the 14-day treatment, mice from all the groups were sacrificed and necropsied. Abdominal visceral organs were initially observed in situ for any noticeable changes/lesions associated with diabetes. Liver, pancreas, and kidney were harvested and examined grossly and histologically.
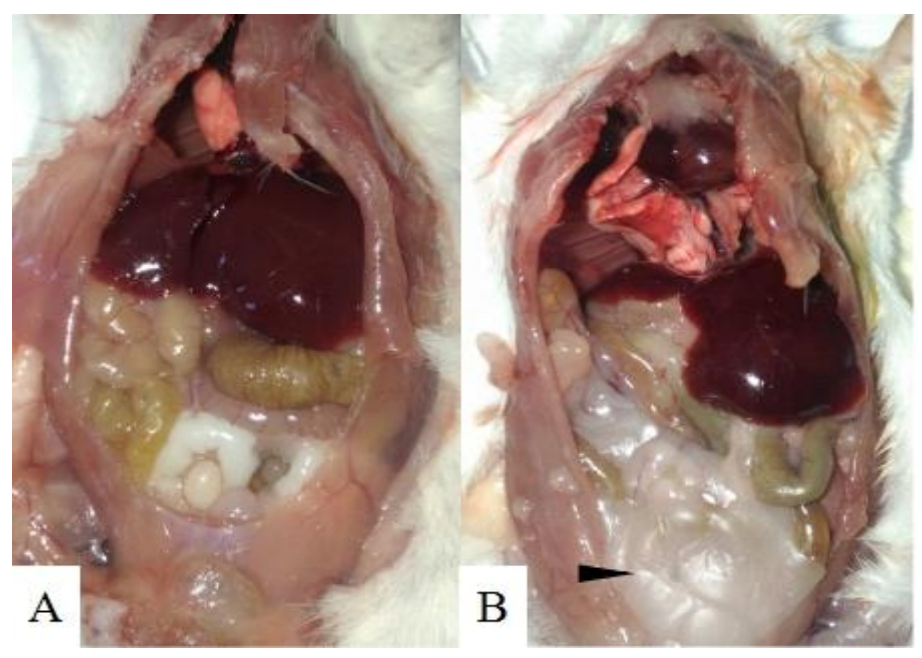

Figure 3 Gross examination of the visceral organs of the negative control group (A), and positive control group (B).

Arrow shows a noticeable accumulation of visceral fats

On gross examination, the abdominal organs of the groups with alloxan-induced diabetes were covered and interlaced with a larger amount of visceral fats, especially perirenal fats, as compared with the negative control group. Liver samples from the negative control group have well-defined edges, no foci of necrosis, congestion or hemorrhages and easy to isolate with the surrounding organs. No notable lesions were found.

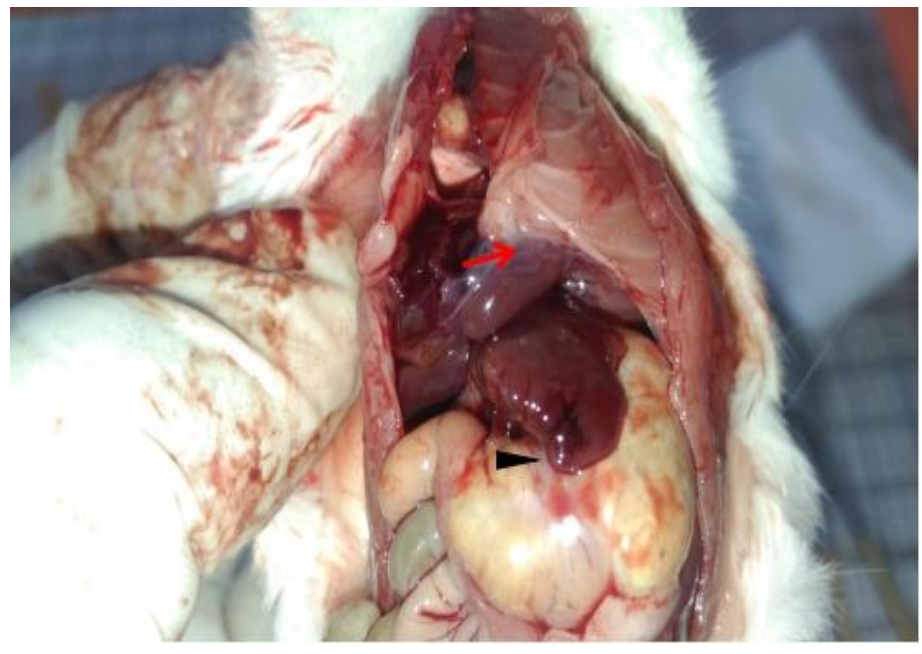

Figure 4 Liver of a positive control group mouse showing adhesion (red arrow) and blunt edges (black arrowhead)

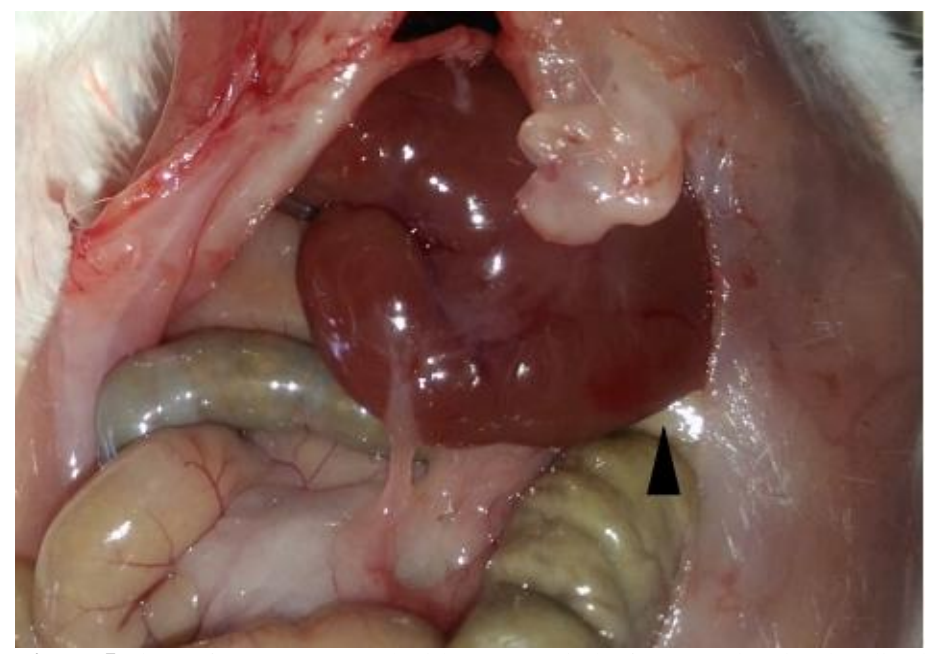

Figure 5 Liver of a mouse treated with 10\% stevia leaf extract showing localized area of hemorrhage (black arrowhead)

Upon gross examination, the liver of mice from the positive control group showed paler color (compared with the negative control group) with relatively larger size, rounded edges, and adhesion to the visceral surface of the abdomen. Group treated with $10 \%$ stevia leaf extract showed hemorrhagic foci on the diaphragmatic surface while groups treated with $60 \%$ and $100 \%$ stevia leaf extracts have no noticeable gross lesion. Similar findings were observed in the study of Abdellatif (2013) where the liver of diabetic mice was mildly enlarged with a rounded inferior margin, smooth capsule and a pale-yellow brown greasy cut surface.

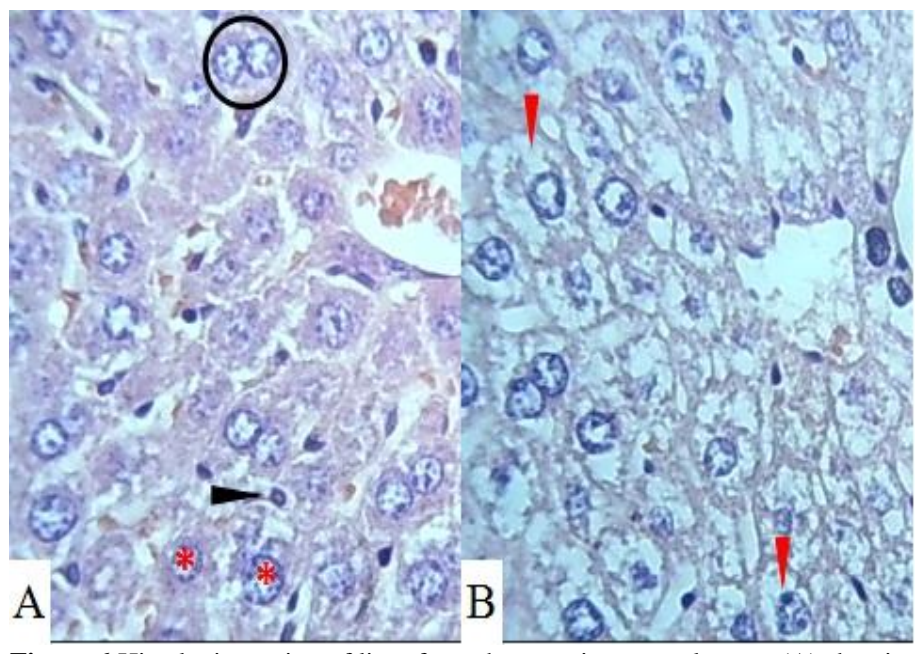

Figure 6 Histologic section of liver from the negative control group (A) showing hepatocyte atrophy (black arrowhead), anisokaryosis $(*)$, and nuclear duplication (encircled); and the positive control group (B) showing cellular swelling (red arrowhead) 
Organs extracted from all the groups were subjected to tissue processing and histopathological examination. Histopathological findings in the liver include: (1) hepatocyte atrophy, anisokaryosis and nuclear duplication in the negative control group, and groups treated with $100 \%$ and $60 \%$ stevia leaf extract; (2) extensive severe acute cellular swelling of hepatocytes in the positive control and glibenclamide-treated groups; while, (3) multiple single cell necrosis (apoptosis) with nuclear duplication and hepatocyte atrophy in the group treated with $10 \%$ stevia leaf extract.

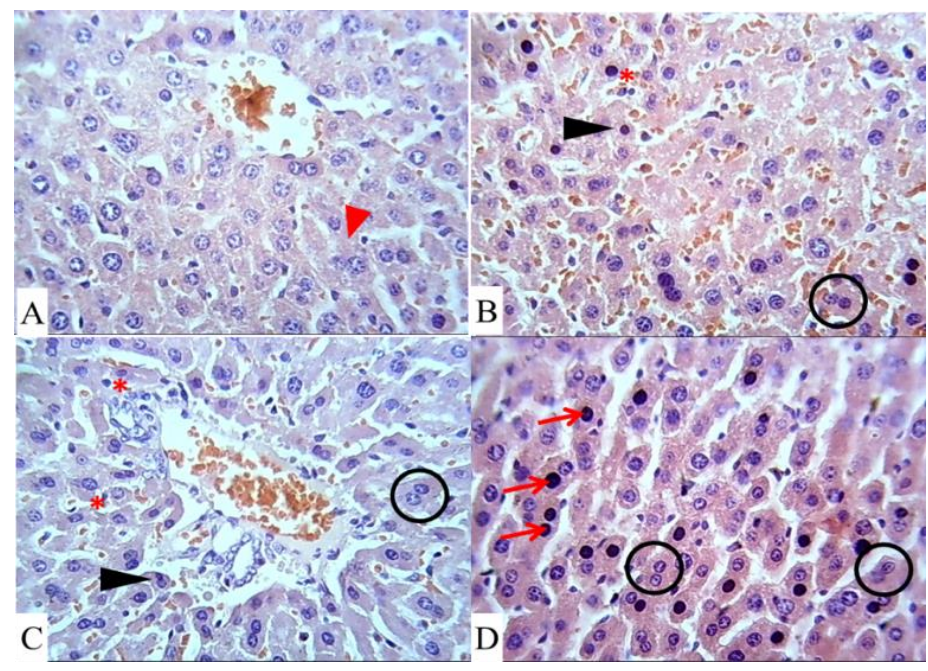

Figure 7 Histologic section of the liver from the group treated with glibenclamide (A), and groups treated with $100 \%$ (B), $60 \%$ (C) and $10 \%$ (D) stevia leaf extract. Cellular swelling (red arrowhead), hepatocyte atrophy (black arrowhead), anisokaryosis $(*)$, nuclear duplication (encircled) and multiple single cell necrosis (red arrow) were observed

According to Abdellatif (2013) and Honjo et al. (1986), cellular swelling may appear as vacuolation/ cellular lucency, and may appear to displace the nucleus, resulting to "signet rings" appearance, which is the classical sign of fatty change, in cases of diabetes in rodents. Furthermore, Abdelattif (2013) pointed out that liver cell damage can be attributed to hyperglycemic episodes which increase the generation of free radicals by glucose auto-oxidation. The increase in the overall stress-causing oxygen free radicals in diabetes could be primarily due to the increase in blood glucose levels and secondarily due to the effects of the diabetogenic agent used, the alloxan.

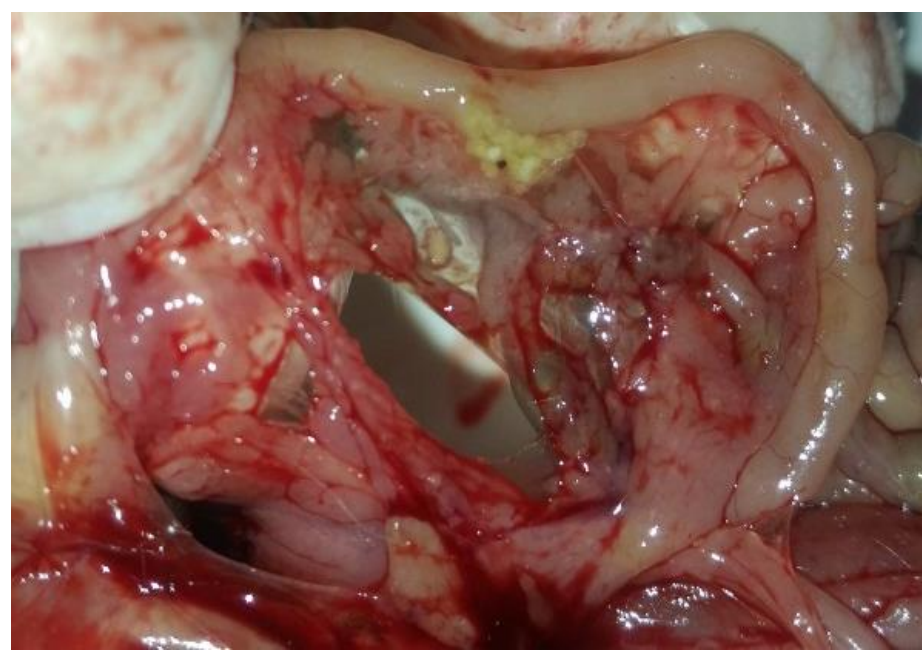

Figure 8 Gross examination of the pancreas of a positive control group mouse

Gross examination of the pancreas showed no outstanding lesion. However, on histopathology, islet degeneration, vacuolation and loss of cytoplasm of pancreatic islet cells were observed. There was a mild islet shape alteration in diabetic groups of which the positive control group showed the most notable changes. Same observations were reported in the studies of Honjo et al. (1986) and Assaei et al. (2016).

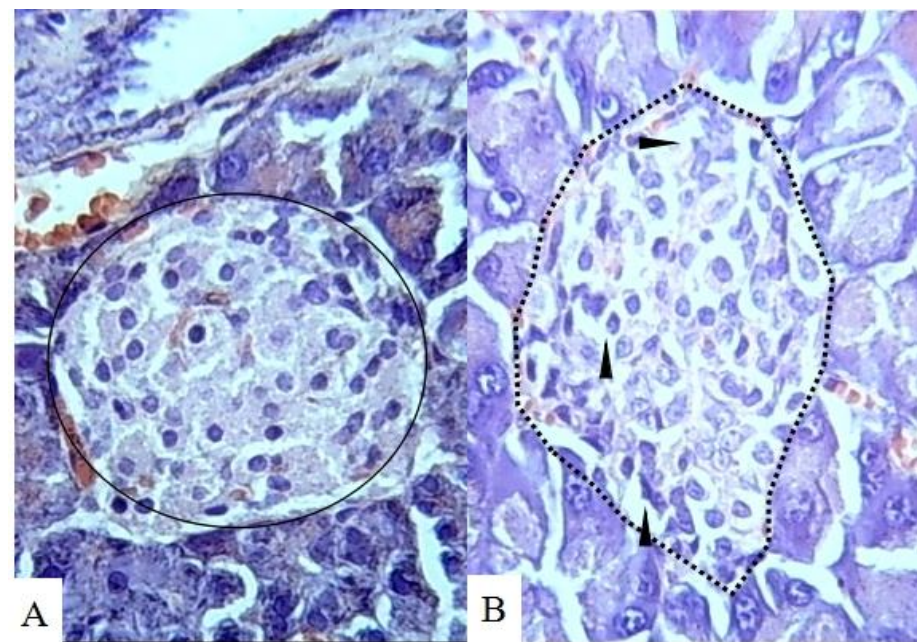

Figure 8 Histologic section (400x magnification) of the pancreatic islet of negative control group (A) with apparently normal appearance, and positive control group (B) with distorted pancreatic islet shape and noticeable vacuolation and loss of cytoplasm (black arrow head)

La Rosa (2009) stressed that pathologic findings in the pancreas are variable and not necessarily dramatic. But rather, the important morphologic changes in diabetes were associated to numerous late systemic complications, because they are the major causes of morbidity and mortality in cases of diabetes mellitus, therefore, absence of gross lesion does not imply normal pancreas, but rather histological examination of the said organ and other tissues involved in the diabetes pathology can elucidate the condition.

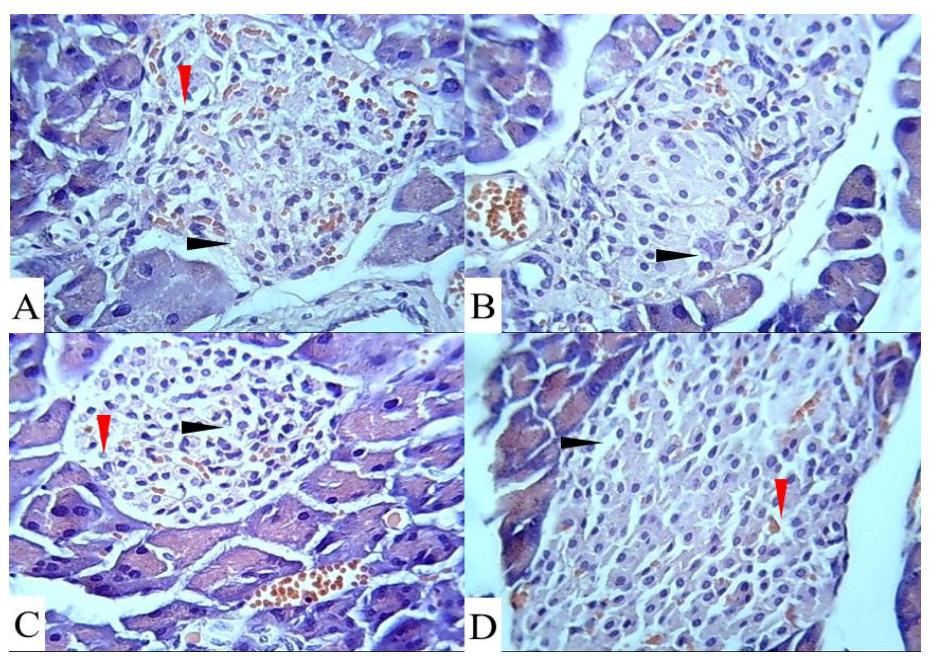

Figure 9 Histologic section (400x magnification) of the pancreatic islet of group treated with glibenclamide (A), and groups treated with $100 \%(\mathrm{~B}), 60 \%(\mathrm{C})$ and $10 \%$ (D) stevia leaf extract. Vacuolation (black arrowhead) and loss of cytoplasm (red arrowhead) of pancreatic islet cells

In the present study, vacuolation and loss of cytoplasm were observed in all groups and more extensive in the groups treated with glibenclamide and $60 \%$ stevia leaf extract. The diabetogenic agent alloxan affects the pancreas by its rapid uptake by pancreatic beta cells, which hastens the reduction process and generates reactive oxygen species (ROS) and superoxide radicals causing cellular and tissue damage (Das et al., 2012). 


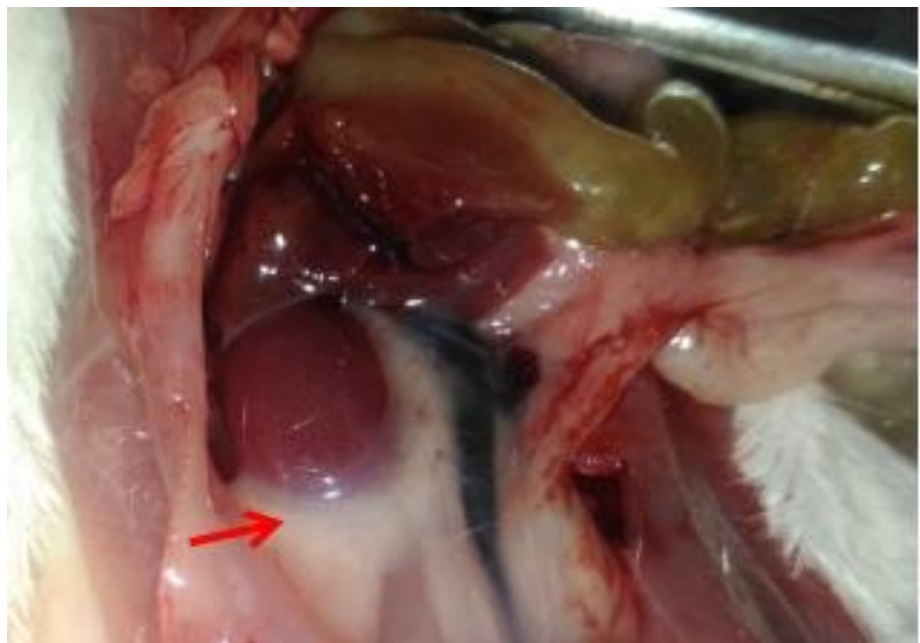

Figure 10 Gross examination of the kidney of a mouse treated with $100 \%$ stevia leaf extract showing dense perirenal fats

Kidneys of groups with alloxan-induced diabetes, whether treated or not, were covered with large amount of perirenal fat. No other lesions were observed grossly. On histopathological examination, glomerular units of kidneys from groups with alloxan-induced diabetes have partial to full desquamation of the glomerular capsule epithelium. Similar findings were reported by Bassey $\boldsymbol{e t} \boldsymbol{a l}$. (2014). There were also deformities in the shape and structure of glomeruli. Gross and histopathological lesions were present on all the groups with alloxaninduced diabetes.

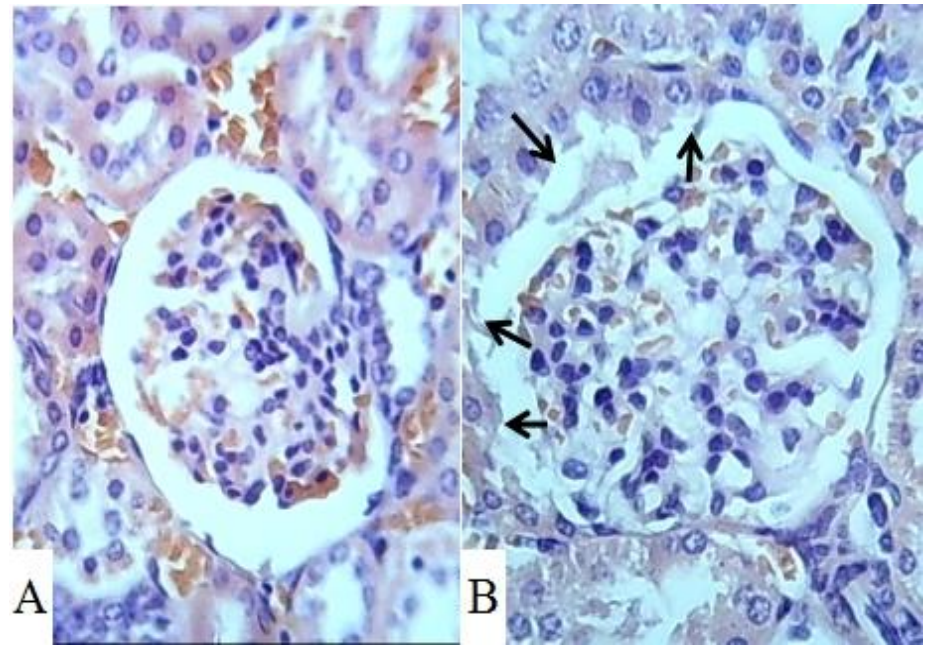

Figure 11 Histologic sections (400x magnification) of the kidney of negative control group (A), and positive control group (B) showing full desquamation of the capsular epithelium of the glomerulus (black arrow)

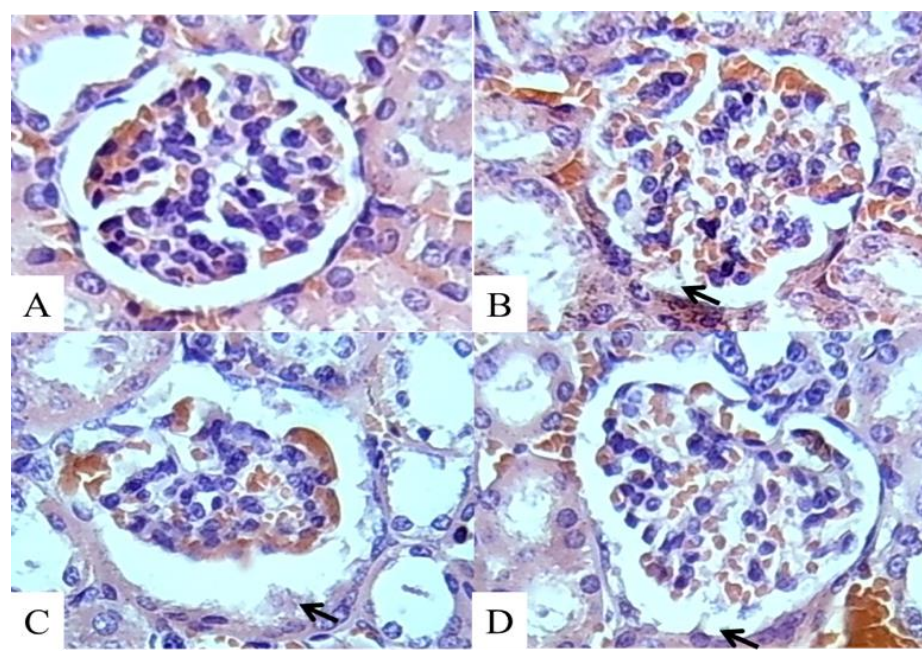

Figure 12 Histologic section (400x magnification) of kidney from group treated with glibenclamide (A), and groups treated with $100 \%$ (B), $60 \%$ (C), and $10 \%$ (D) stevia leaf extract showing desquamation of the glomerular capsule (black arrow)
Gross appearance of the kidney may be normal even with an underlying condition. Morphologic changes in diabetic nephropathy grossly were the ultimate effect of damage in renal compartments- glomeruli, tubules, interstitium, and vessels histologically. Pathogenesis of diabetic nephropathy in cases of diabetes mellitus is that hyperglycemia impairs autoregulation within the glomerulus by activating the local, intrarenal renin-angiotensin-aldosterone system, thus, compounding the hyperglycemia-induced injury (Raparia $\boldsymbol{e t}$ al., 2012).

\section{CONCLUSION}

Even though there is modernization and advancement in treating common ailments, people tend to look at natural and safer but effective ways on alleviating conditions such as diabetes mellitus. Alternative treatment has been making its way back on mainstream medicine, of which stevia is an example. Based on the fore mentioned findings, stevia leaf extract has similar effects (but of different extent) as the pharmacological agent, glibenclamide. Results on weight changes suggest that weight loss by diabetes were not affected by treatment. Posttreatment fasting blood glucose level shows that stevia leaf extracts were effective in lowering BGL. Among treatment levels, 10\% stevia shows the best result in OGTT. Stevia leaf extract possibly has histo-protective/ regenerative effects since it was able to lessen the extent of damage in organs of interest, as compared with the untreated positive control.

\section{REFERENCES}

ABDELLATIF, N.A. (2013). Protective effect of Nigella sativa against diabetic complication of the liver in white male rats. The Egyptian Journal of Hospital Medicine, 53, 1072-1082. http://doi.org/10.12816/0001669

AMERICAN DIABETES ASSOCIATION. (2010). Diagnosis and classification of diabetes mellitus. Diabetes Care, 33(1), 62-69. http://doi.org/10.2337/dc10S062

ASSAEI, R., MOKARRAM, P., DASTGHAIB, S., DARBANDI, S., DARBANDI, M., ZAL, F., \& RANJBAR OMRANI, G.H. (2016) Hypoglycemic effect of aquatic extract of stevia in pancreas of diabetic rats: PPAR $\gamma$-dependent regulation or antioxidant potential. Avicenna Journal of Medical Biotechnology, 8(2), 65-74.

BASSEY, E.S., OYEBADEJO, S.O., \& ATASIE, O.C. (2014). Histopathological assessment of the kidney of alloxan induced diabetic rat treated with macerated Allium sativum (garlic). Asian Journal of Biomedical and Pharmaceutical Sciences, 4(35), 13-17. http://doi.org/10.15272/ajbps.v4i35.214

CHEHADE, J.M., GLADYZS, M., \& MOORADIAN, A.D. (2013) Dyslipidemia in type 2 diabetes: prevalence, pathophysiology, and management Drugs, 73(4), 327-39. http://dx.doi.org /10.1007/s40265-013-0023-5

DAS, J., VASAN, V., \& SIL, P.C. (2012). Taurine exerts hypoglycemic effect in alloxan-induced diabetic rats, improves insulin-mediated glucose transport signaling pathway in heart and ameliorates cardiac oxidative stress and apoptosis. Toxicology and Applied Pharmacology, 258(2), 296-308. http://doi.org/10.1016/j.taap.2011.11.009

EISENBERG, D.M., DAVIS, R.B., ETTNER, S.L., APPEL, S., WILKEY, S., VAN ROMPAY, M. \& R.C. KESSLER. (1998). Trends in alternative medicine use in the United States, 1990-1997: results of a follow-up national survey. JAMA, 280(18), 1569-75. http://dx.doi.org / 10.1001/jama.280.18.1569

FAWCETT, A. (2012). Animal Research Review Panel 2: Guidelines for housing of Mice in Scientific Institutions. Animal Welfare Unit, NSW Department of Primary Industries

https://www.animalethics.org.au/_data/assets/pdf_file/0004/249898/Guideline-

22-mouse-housing.pdf

GUPTA, D., KONO, T., \& EVANS-MOLINA, C. (2010). The role of peroxisome proliferator-activated receptor $\gamma$ in pancreatic $\beta$ cell function and survival: therapeutic implications for the treatment of type 2 diabetes mellitus. Diabetes Obesity and Metabolism, 12(12), 1036- 1047. http://dx.doi.org /10.1111/j.1463-1326.2010.01299.x

HONJO, K., DOl, K., DOl, K., \& MITSUOKA, T. (1986). Histopathology of streptozotocin-induced diabetic DBA/2N and CD-1 mice. Laboratory Animals, 20(4), 298-303. http://doi.org/10.1258/002367786780808695

KIM, D., KIM, S., KIM, S.K., PARK, S., \& SONG, K. (2016). Is an oral glucose tolerance test still valid for diagnosing diabetes mellitus? Diabetes \& Metabolism Journal, 40(2), 118-128. http://doi.org/118-128. 10.4093/dmj.2016.40.2.118 JEPPESEN, P.B., GREGERSEN, S., POULSEN, C.R., \& HERMANSEN, K (2000). Stevioside acts directly on pancreatic beta cells to secrete insulin: actions independent of cyclic adenosine monophosphate and adenosine triphosphatesensitive K+-channel activity. Metabolism, 49(2), 208-214 https://doi.org/10.1016/S0026-0495(00)91325-8

LA ROSA, F.G. (2009). Pancreas pathology and diabetes mellitus. Child Health Associatel Physician Assistant (CHA/PA) Program

LACHIN, T., \& REZA, H. (2012). Antidiabetic effect of cherries in alloxan induced diabetic rats. Recent Patents on Endocrine, Metabolic \& Immune Drug Discovery, 6(1), 67-72. http://doi.org/10.2174/187221412799015308 
MISRA, H., SONI, M., SILAWAT, N., MEHTA, D., MEHTA, B.K., \& JAIN, D.C. (2011). Antidiabetic activity of medium-polar extract from the leaves of Stevia rebaudiana Bert. (Bertoni) on alloxan-induced diabetic rats. Journal of Pharmacology and Bioallied Sciences, 3(2), 242-248. http://dx.doi.org /10.4103/0975-7406.80779

MOUSE METABOLIC PHENOTYPING CENTER. (2012). Oral Gavage Glucose Tolerance Test (OGTT)

RAPARIA, K., USMAN, I., \& KANWAR, Y.S. (2013). Renal morphologic lesions reminiscent of diabetic nephropathy. Archives of Pathology \& Laboratory Medicine, 137(3): 351-359. http://doi.org/10.5858/arpa.2012-0243-RA

PROKS, P., REIMANN, F., GREEN, N., GRIBBLE, F., \& ASHCROFT, F. (2002). Sulfonylurea stimulation of insulin secretion. Diabetes, 51( Suppl 3), S368-S376. http://doi.org/10.2337/diabetes.51.2007.s368

SICREE, R., SHAW, J., \&ZIMMET, P. (2006). The Global Burden. Diabetes and Impaired Glucose Tolerance. Prevalence and Projections. Diabetes Atlas, 3RD Brussels: International Diabetes Federation. 16-103

SINGH, M.P., \& PATHAK, K. (2015). Animal models for biological screening of anti-diabetic drugs: an overview. European Journal of Experimental Biology, 5(5):37-48.

SOKOLOVSKA, J., ISAJEVS, S., SUGOKA, O., SHARIPOVA, J. PARAMONOVA, N., ISAJEVA, D., ROSTOKA, E., SJAKSTE, T., KALVINSH, I., \& SJAKSTE, N. (2012). Comparison of the effects of glibenclamide on metabolic parameters, GLTU1 expression, and liver Injury in rats with severe and mild streptozotocin-induced diabetes mellitus. Medicina (Kaunas), 48(10), 532-543

SYTAR, O., BORANKULOVA, A., SHEVCHENKO, Y., WENDT, A., \& SMENTANSKAL, I. (2015). Antoxidant activity and phenolics composition in Stevia rebaudiana plants of different orgin. Journal of Microbilogy, Biotechnology and Food Sciences, 5(3), 221-224. http://doi.org/10.15414/jmbfs.2015/16.5.3.221-224

WORLD HEALTH ORGANIZATION. (1999). Department of Noncommunicable Disease Surveillance. Definition, diagnosis and classification of diabetes mellitus and its complications; Geneva. 